\title{
Current status of thermionic conversion of solar energy
}

\author{
O. C. Olawole ${ }^{1,2, *}$, D. K. De ${ }^{1,3}$, S. O. Oyedepo ${ }^{4}$, O. F. Olawole ${ }^{5}$ and E. S. Joel ${ }^{1}$ \\ ${ }^{1}$ Department of Physics, Covenant University, Ogun State, Nigeria \\ ${ }^{2}$ Division of Computational Physics, Institute for Computational Science, Ton Duc Thang University, Vietnam \\ ${ }^{3}$ Sustainable Green Power Technologies, Mansfield, Texas, 76063, USA \\ ${ }^{4}$ Department of Mechanical Engineering, Covenant University, Ogun State, Nigeria \\ ${ }^{5}$ Department of Physics, Mountain Top University, Ibafo, Ogun State, Nigeria
}

Recent advances in science and technology of materials fabrication, engineering of work functions, and micrometer gap machining between emitter and collector are making thermionic conversion/converter (TEC) of solar energy an emerging technology. As the converter is the lightest of all devices with highest direct power conversion density (per unit area of the converting surface), it has, potential for substituting photovoltaic technology to a large extent and for deployment in space as a power source. This article summarizes the current efforts/technologies in the field, and discusses their inherent merits and demerits towards realizing the goal of achieving high conversion efficiency and simulation of performance evaluation of a solar TEC. We also discuss the use of both metals and nanomaterials, critical roles of work functions of both emitter and collector, collector temperature, absorptivity and emissivity of the surfaces, radiation losses, and use of both metals and nanomaterials in the efficiency of conversion of solar energy. We further deal with the role of correcting thermionic emission current density equation in the simulation of solar TEC performance. We discuss briefly the possible methods of space-charge control in future in a solar TEC.

Keywords: Emission, solar energy, thermionic conversion, work function.

TAPPING the thermal technology of solar energy is the main focus of researchers compared to other sources of energy generation such as nuclear reactors, combustion of fossil fuel and nuclear energy, because of its renewable nature. In harnessing this energy, researchers have been probing several efficient converters that could give desirable efficiency with less toxic impact on the environment. Therefore, thermionic energy converter (TEC) with unmatchable features of eco-friendly, immovable parts, flexibility and noiseless nature has the potential to convert solar energy to electrical energy through recent advancements of nanoengineering.

\footnotetext{
*For correspondence.

(e-mail: olukunle.olawole@covenantuniversity.edu.ng)
}

Also, TEC is easy to maintain and has higher efficiency potential close to the Carnot engine, even though there exist limiting factors such as work function of the materials, space charge build-up in the gap between emitter and collector of the TEC, heat loss, as well as physical and chemical factors. Specifically, the heat loss factor can be minimized to achieve optimum performance that is in tandem with the performance of the Carnot engine ${ }^{1,2}$. In recent time, TECs have been modelled as standalone systems with efficiencies $>50 \%$ and also as combinedcycle systems with efficiencies $>60 \%$ (ref. 3 ).

\section{Evolution of thermionic energy conversion technology}

The earlier idea of converting heat to electrical energy via thermionic energy was first conceived by Schlichter in 1915 (ref. 4), which later led to scientific collaboration between the then USSR, and USA in the 1950s to set up a thermionic energy converter that would power spacecraft $^{4,5}$. Thereafter, a team of researchers in USA launched a thermionic nuclear fuel element (TFE) that worked at a high temperature for $12,500 \mathrm{~h}$. The invention of Mark III reactor helped USA develop a TEC with an efficiency of $7-11 \%$, and power output of $150 \mathrm{~W}$ at elevated temperature ${ }^{6}$. However, the technology faced harsh failure due to undying interest in the photovoltaic technology in the United States at that time. The heat source for a TEC is the major problem. So far, developmental work has focused on TEC systems using heat from a nuclear reactor aboard a spacecraft. The systems recorded efficiencies from $12 \%$ to $15 \%$ when operating at $600^{\circ}-$ $1200^{\circ} \mathrm{C}$. Interest in the use of TEC for space programmes died down after 1973, except for a vapour thermionic energy converter (VTEC) with a circulating liquid metal source $^{7}$ that was built as topping engine for a fusion power plant with $47 \%$ efficiency and operating temperature of $1370 \mathrm{~K}$ (ref. 7). Consequently, TEC has existed as co-generator with steam turbine Rankine and Sterling engines for solar electricty ${ }^{8}$. In addition, high temperature at the emitter surface is needed to achieve high current density. Solar energy can be concentrated via suitable devices 
such as parabolic concentrator, parabolic trough mirror, heliostat, etc. and abundant sunshine is available in many parts of the world (Asian, African countries and in several parts of USA). Temperatures as high as $2000 \mathrm{~K}$ can be reached with a concentrator factor of 1500 and solar insolation of $650 \mathrm{~W} / \mathrm{m}^{2}$. This is kindling new interest in solar thermionic power generation ${ }^{5,9-12}$.

USSR succeeded in building a TEC engine with 5$6 \mathrm{~kW}$ power source in order to launch a satellite into space $^{13-15}$. In the $1980 \mathrm{~s}$, the US researchers did not build any thermionic fuel element (TFE) but only proposed the average lifespan of TFE to be within 3-7 years ${ }^{15}$.

Consequently, Naito et al. ${ }^{16}$ recorded the efficiency of their thermionic-thermoelectric engine as approximately $40 \%$. In 1998, the research group of Japan Solar Upper Stage (JSUS) built a TEC that operated at power output $17.9 \mathrm{~W}$ and efficiency $23.2 \%$. The effect of Smestad ${ }^{17}$ for higher power output and efficiency with carbonless emission in the environment led to the development of photoelectric-thermionic engine system. Subsequently, a high power advanced low-mass solar thermionic engine converter (HPALMSTEC) that was theoretically conceptualized to operate at a power output of $50 \mathrm{~kW}$ was experimentally achieved in 2006 with efficiency of $6.5 \%$ (ref. 18). Yaghoobi et al. ${ }^{19}$ used carbon nanotube as the emitter in TEC, which gave an efficiency of $10^{-4} \%$. Buencuerpo et $a l .{ }^{20}$ utilized light trapping to increase the efficiency of photo-enhanced thermionic emission (PETE) by $10 \%$. Therefore, the essence of green energy technology is to provide a low cost alternative source of energy that is environmentally friendly and highly efficient. Moreover, photo-enhanced thermionic emission (PETE) as a topping cycle in concentrated solar thermal electricity generation, is expected to enable total system efficiencies in excess of $52.9 \%$ (refs 21,22 ). In addition, a theoretical model calculated the efficiency of PETE at a concentration ratio of 1000 as $70.4 \%$, which is yet to be experimentally validated ${ }^{21,23}$. In recent times, the Stanford Linear Accelerator Centre (SLAC)/Stanford University research team USA has focused on a new solid-state energy conversion technology using microfabricated hetero-structure semiconductor cathodes with appropriate band engineering and photon-enhanced thermionic energy converters (PETECs). The microfabrication allows a small gap (a few microns) between the emitter and collector and thus reduces the space-charge effect drastically ${ }^{24-27}$.

Wang et al. ${ }^{28}$ used $\mathrm{NaCsSb}$ as an emitter in the PETE engine to obtain $0.0197 \%$ efficiency. Liu et al. ${ }^{29}$ found the efficiency of GaAs nanowire cathode doped exponentially as $19.46 \%$ and GaAs nanowire cathode with aluminium composition matrix as $15.8 \%$. Smerdov et al. ${ }^{30}$ concluded that the wafer production of GaAs is not technologically simple and that GaAs substrate is expensive. Therefore, their fabricated porous silicon (PS) and PSbased composition matrix yielded an efficiency of $20 \%$. The flexibility of tuning the sensitivity of the bandgap, morphology and surface structure of PS and PS-based in TEC to a desirable point are of great interest to research$\mathrm{ers}^{30,31}$. Table 1 elucidates the progress made so far in the development of TEC prototype, both experimentally and theoretically.

\section{Principles of thermionic energy converter}

In Figure 1, two metals $\mathrm{A}$ and $\mathrm{B}$ are shown with work function $W_{A}<W_{B}$. For example, $A$ can be aluminium $(W \sim 4.2 \mathrm{eV})$ and $B$ can be gold $(W \sim 5.3 \mathrm{eV})$. The vacuum level, $E_{v}$ for both is the same. The work function is by $W=E_{v}-\mu$. Since $W_{A}<W_{B}$ and $E_{v}$ is the same for the two bare metals, $\mu_{A}>\mu_{B}$. When they are connected by a perfectly conducting wire, the statistical physics demands that their chemical potentials $(\mu)$ be aligned (Figure 2). Because of the lower work function, the free electrons in metal $A$ have higher chances to cross the vacuum level and go to metal $B$ than the electrons from $B$ coming to $A$. To see this in another way, the chemical potential depends on electron concentration $\left(5.90 \times 10^{28} \mathrm{~m}^{-3}\right.$ and $2.1 \times 10^{29} \mathrm{~m}^{-3}$ in $\mathrm{Au}$ and $\left.\mathrm{Al}\right)$; therefore, some electrons must flow from $A$ to $B$ to make their chemical potentials the same when they are connected. This is also consistent with the fact that electrons in Al near the Fermi level have higher energies than those in Au. Thus, the flow of electrons is necessary for the chemical potentials to be aligned when they are connected electrically. This makes metal $B$ have a negative potential and metal $A$ have a positive potential. Thus, there will be a potential difference between metals $A$ and $B$. Once that potential difference, $V_{A B}=\left(W_{B}-W_{A}\right) / e$, is fully set up, it will prevent further flow of electrons from $A$ to $B$. Note that this potential difference cannot constitute a current through the wire as it would disrupt the Fermi energy (chemical potential) equilibrium.

After this initial adjustment, electrons in both metals still have the maximum energy at $E_{\mathrm{F}}$, particularly at $0 \mathrm{~K}$. There will be no electron flow between the two metals at $0 \mathrm{~K}$. If metal $B$ (emitter; gold in Figure 1) is heated to a high temperature, then a sufficient number of electrons will reach the vacuum level in $B$, overcoming the work function $W_{B}$ and with kinetic energy. These electrons will experiences an electric field that will sweep them to metal $A$ in the form of emission (from $B$ to $A$ ) (similar to the injection of electrons in a forward-biased $P-N$ junction). It will constitute an electric current, which can drive a load (Figure 2) under the voltage $\left(W_{B}-W_{A}\right) / e$, and one can get work output. Note that the reverse is not possible, i.e. electrons thermionically emitted from $A$ will have to work against the barrier to reach $B$, and will not deliver any output power. This is the principle of a TEC (Figure 2). If $B$ is not connected to $A$, then electrons from the hot metal surface $B$ will be emitted out of the metalthermionic emission. Such thermionic emission will 


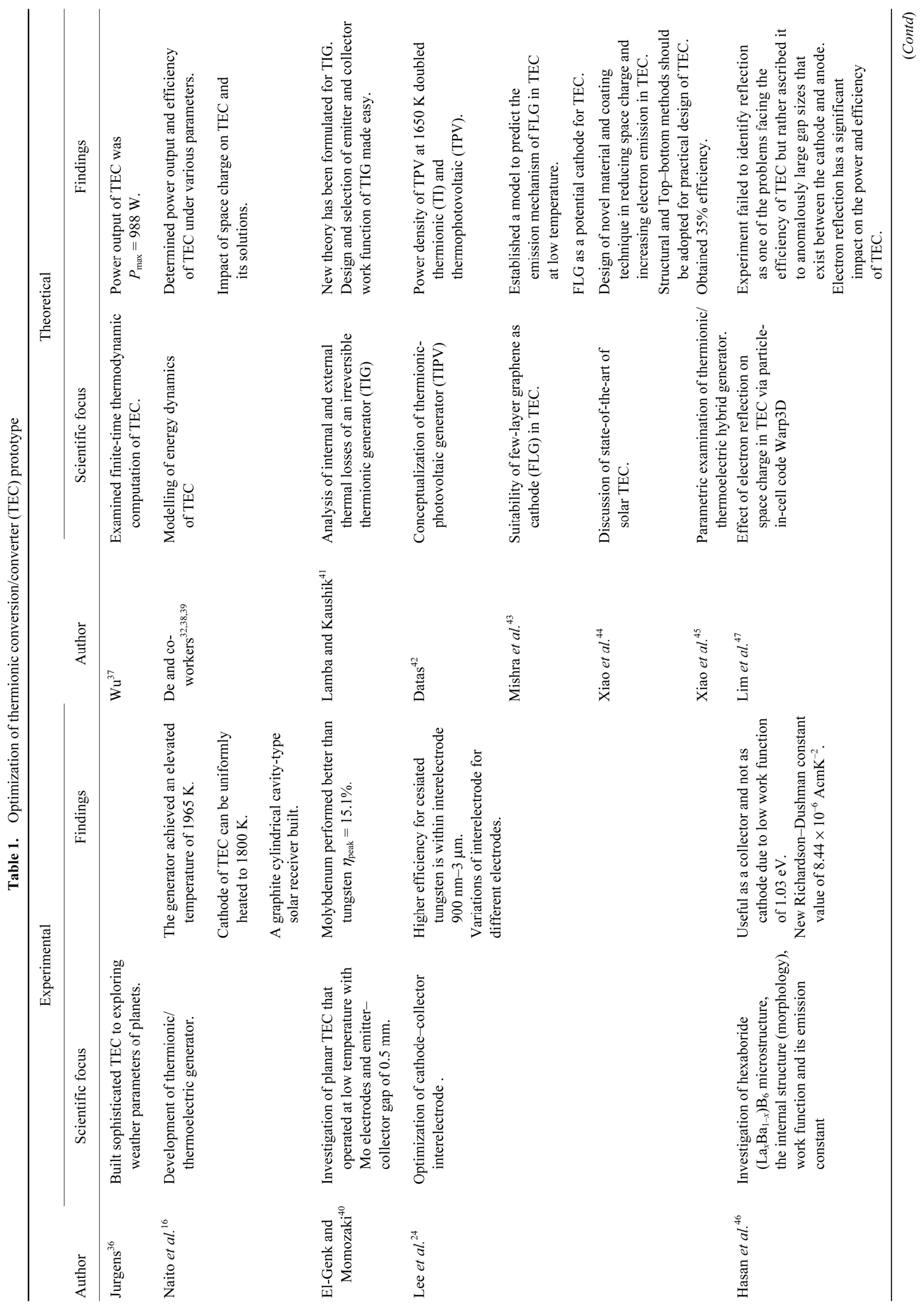




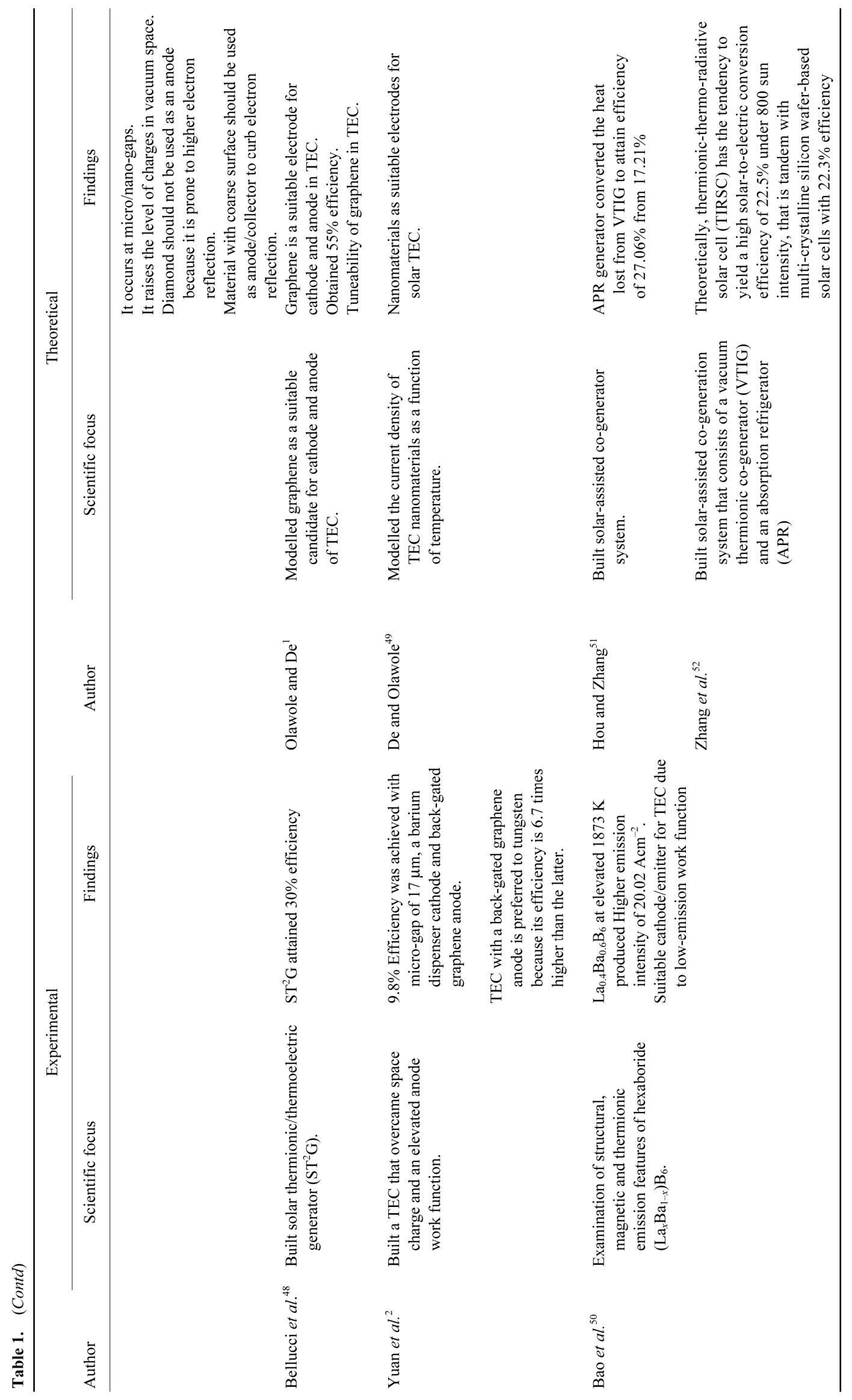


continue if $B$ remains hot and electrically grounded to supply the electrons. In the case of TEC, i.e. when $B$ and A are connected, the emitted electrons are collected by $A$ (anode or collector) and return to $B$, with the chemical potentials remaining aligned. Thus, the energy of the electrons is delivered to the external load (Figure 2). This continues if energy is supplied to $B$ to keep it hot. Thus, heat energy is converted to electrical energy. This is the principle of the TEC. Metal $A$ will also emit electrons in a TEC. The corresponding current density will tend to oppose the current density from $B$ for external work output. Thus, it is important in a TEC to have the temperature of $A$ (collector) much lower than that of $B$ (emitter). The output power in a TEC (Figure 2), $P_{\text {out }}=\left(I_{\mathrm{e}}-I_{\mathrm{c}}\right)$ $\left(W_{B}-W_{A}\right) / e$, where $I_{\mathrm{e}}$ is the emitter current and $I_{c}$ is the collector current. Again, the separation between emitter and collector has to be very small to reduce the spacecharge effect, especially in the absence of a gate and magnetic field control.

To generate a sizable amount of electrical power (several kWs-MWs) from the sun using a thermionic converter, one needs a large-sized parabolic concentrator with good parabolicity ${ }^{18}$. The world's largest parabolic

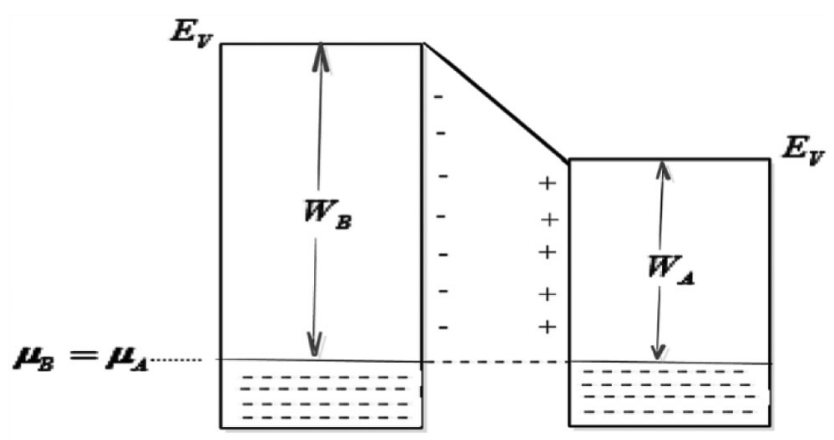

Figure 1. When two metals are connected electrically, electron flows from metal $A$ (say, Al) to metal $B(\mathrm{Au})$. Thus a potential barrier is formed $\left(W_{A}<W_{B}\right) /(e)$ that prevents further flow of electrons from $A$ to $B$ (ref. 1).

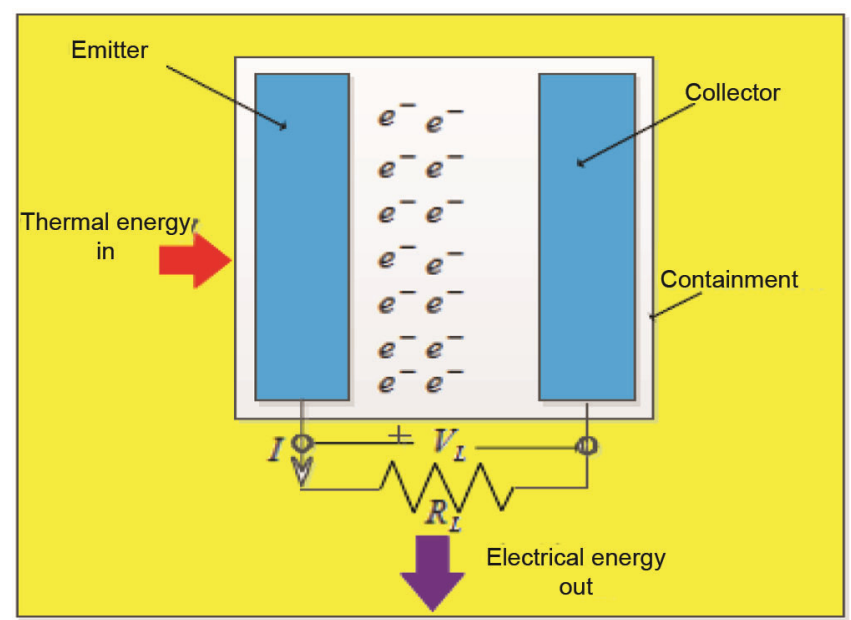

Figure 2. Schematic diagram of thermionic energy converter ${ }^{1}$. antenna (diameter $305 \mathrm{~m}$ ) used in world's largest radio telescope is seen in Arecibo (Puerto Rico). If such antenna could have a perfectly reflecting mirror and light enough to track the sun and its parabolicity good enough to focus the concentrated solar energy onto an area of 4 sq. $\mathrm{m}$ (where the main part of TEC would be placed). And with average solar insolation of $600 \mathrm{~W} / \mathrm{m}^{2}$ for $8 \mathrm{~h}$ a day, a total of $140 \mathrm{MWh}$ of energy can be generated per day, assuming a modest TEC efficiency of $40 \%$. Even at reasonable efficiency of $20 \%$, the total energy output is $70 \mathrm{MWh}$ of energy per day (without good space-charge control). Obstacles to be overcome to achieve this possibility are the following: (i) covering the large parabolic surface with highly reflecting coating; (ii) making such a mirror light enough for solar tracking; (iii) using materials with low work function (in the range of 2.5-1 eV) which are capable of withstanding temperature in the range 3500-2000 K; (iv) using proper device to control temperature of the collector in relation to the emitter temperature to achieve the desired efficiency; (v) perfect space-charge control to achieve the desired efficiency (50\% or higher) and (vi) light permanent magnets with a uniform field of $1000 \mathrm{G}$ over large area of the emitter and collector (4 sq. m).

In concentrated solar thermal and concentrated photovoltaic stations, TEC could convert the heat loss into electrical power with considerably good efficiency. However, to the best of our knowledge, a practical solar TEC has not been realized yet. De and Olukunle ${ }^{32}$ first carried out conservation of energy principle, the dependence of efficiencies of solar TEC on work functions of the emitter and collector, and their temperatures, and how the latter terms would be dictated by the incident solar power density, except for their earlier published work ${ }^{1,33}$. Many emitter materials have work functions in the range 3$4.5 \mathrm{eV}$. These require very high temperatures (above $2000 \mathrm{~K})$ to generate sizable current density. Except for a few (such as tungsten), most materials have melting points below $2000 \mathrm{~K}$ and therefore are not suitable for high-temperature TEC.

As current density at a given temperature increases exponentially with lowering of work function for TEC applications, research is now focused on fabrication of materials with low work functions. Such materials should also tolerate fairly high temperatures $\sim 2000 \mathrm{~K}$. Polycrystalline diamond films exhibited a work function of $0.9 \mathrm{eV}$ when doped with phosphorus. However, they were stable only up to $765^{\circ} \mathrm{C}$ (ref. 34). Nitrogen-incorporated, ridged nano-diamond films on silicon substrates attained a work function of $1.39 \mathrm{eV}$ and were thermally stable at temperatures up to at least $900^{\circ} \mathrm{C}$ (ref. 35).

\section{Technological hurdles}

Basically, TEC is confronted with two scientific issues, namely electrode materials with low work functions that 
Table 2. Overview of electrodes in a TEC (ref. 44)

\begin{tabular}{|c|c|c|c|c|c|c|}
\hline$W_{\mathrm{e}}(\mathrm{eV})$ & $W_{\mathrm{c}}(\mathrm{eV})$ & $T_{\mathrm{e}}(\mathrm{K})$ & $T_{\mathrm{c}}(\mathrm{K})$ & $P_{\text {out }}(\mathrm{W})$ & $\eta(\%)$ & References \\
\hline Rhenium & Molybdenum & 1990 & - & 114 & 7.0 & 6 \\
\hline Molybdenum & Molybdenum & 1850 & - & 17.9 & 23.2 & 69 \\
\hline Tungsten & Molybdenum $(0.03)+$ niobium & 1670 & - & 30 & - & 70 \\
\hline Tungsten oxide & Polycrystalline tungsten & 1800 & 973 & 6 & - & 71 \\
\hline Tungsten & Nickel & 1420 & 850 & 1 & - & 72 \\
\hline Grooved molybdenum & Molybdenum & 1500 & 728 & 0.95 & - & 73 \\
\hline $\mathrm{ZrO}_{2}-\mathrm{Mo}$ & $\mathrm{ZrO}_{3}-\mathrm{MO}$ & 1523 & - & 2.5 & - & 74 \\
\hline $\mathrm{SiC}-\mathrm{C}-\mathrm{W}$ & Nickel & 1630 & 900 & 2.1 & - & 75 \\
\hline Molybdenum & Stainless steel & 1600 & 700 & 6 & - & 76 \\
\hline Molybdenum & Molybdenum & 1650 & 750 & 4 & - & 77 \\
\hline $\mathrm{SiC}-\mathrm{C}-\mathrm{W}$ & Nickel & 1375 & 900 & 0.2 & 0.5 & 78 \\
\hline Tungsten & Nickel & 1453 & 591 & 4.2 & - & 79 \\
\hline Molybdenum & Molybdenum & 1573 & 1073 & 0.34 & 4.90 & 80 \\
\hline Molybdenum & Molybdenum & 1673 & 973 & 2.27 & 15.10 & 81 \\
\hline Tungsten & Niobium & 1600 & 1000 & 1.76 & 7.90 & 82 \\
\hline Grooved molybdenum & Smooth molybdenum & 1673 & 873 & 2.18 & 12.90 & 82 \\
\hline Smooth molybdenum & Grooved molybdenum & 1673 & 873 & 2.56 & 14.70 & 82 \\
\hline Smooth molybdenum & Smooth molybdenum & 1673 & 873 & 3.74 & 17 & 82 \\
\hline Grooved molybdenum & Grooved molybdenum & 1673 & 873 & 1.86 & 11.20 & 82 \\
\hline Graphene & Metallic & 900 & 450 & - & 45 & 56,83 \\
\hline Graphene & Metallic & 1200 & 400 & - & 56 & 43 \\
\hline Graphene & Graphene & 1500 & 1000 & - & 63.8 & 1 \\
\hline
\end{tabular}

$W_{\mathrm{e}}$ represents the work function of the emitter, $W_{\mathrm{c}}$ is the work function of the collector, $T_{\mathrm{e}}$ is the temperature of the emitter, $T_{\mathrm{c}}$ is the temperature of the collector, $P_{\text {out }}$ is the power output and $\eta$ is the efficiency.

can withstand elevated temperatures and space-charge barrier that reduces the current density, power output and efficiency.

Next we discuss how nanotechnology seeks new emitters, collectors and solves the problem of space charge that exists within the emitter-collector of TEC.

\section{Emitter work function}

The physics of thermionic emission suggests that the emitter must be made of a material with low work function that can withstand elevated temperatures such as concentrated sunlight. In search of these materials, a tungsten emitter was doped with scandium oxide at elevated temperature, which reduced the work function of tungsten drastically and led to higher current density ${ }^{53,54}$. A polycrystalline diamond exhibited a work function of $1.4 \mathrm{eV}$, when it was doped with nitrogen ${ }^{9,10}$. More so, the addition of caesium to the platinum surface resulted in a low work function of $1.4 \mathrm{eV}$ (ref. 55). Also, the work function of passivated hydrogen (100) $p$-type silicon substrate was tuned from 4.7 to $1.35 \mathrm{eV}$ through the inclusion of potassium on silicon lattice ${ }^{12}$. In recent times, carbon nanotubes and graphene as emitters have been considered both experimentally and theoretically because of their excellent properties ${ }^{1,11,56-58}$. Their higher work functions have been reduced to desirable tolerance via barium-doped diamond ${ }^{12,59}$, emerging nanoscience and nanoengineering ${ }^{19,34,35}$. Consequently, the work function of mono-walled and poly-walled carbon nanotubes has been successfully intercalated at low temperature with potassium to $2 \mathrm{eV}$ (ref. 60). Figure 3 shows vertical zincoxide tiny-wires deposited on the surface of the emitter because of their high field potential, high aspect ratio, exceptional quantum confinement attributes and easy deposition processes. Therefore, chemical vapour deposition together with catalytic gold was adopted to grow the tiny wires on the emitter ${ }^{61}$. Studies have proven that the electron negative affinity (NEA) from diamond, boron nitride and aluminium nitride can reduce higher work functions in emitters to lower values suitable for TEC applications, without compromising their higher electron emission property ${ }^{10,59,62,63}$. Alternatively, atomic layer deposition of thin oxide on emitter ${ }^{63}$ and the use of nanomaterials like graphene (emitter) as are suitable in a TEC (Table 2).

\section{Collector work function}

The fundamental role of using low collector work function in realizing higher power output in a TEC cannot be undermined. As such, obtaining substantial power output in the TEC configuration demands that the collector work function should be smaller than the emitter work function, and that the input voltage is approximately equivalent to the change in cathode and anode work functions $^{33,63}$. Additionally, the physics of condensation of emitted electrons on the collector is such that its work function must be smaller than the vacuum level so as to reduce the thermal loss that exists between the emitter 
and the collector ${ }^{64}$. Also, it has been observed that during heat radiation transfer, an anode with higher thermal reflectivity possesses the ability to drastically increase the efficiency of a TEC ${ }^{1,63}$.

Over the years, researchers have made limited efforts to probe the influence of higher collector work function and its surface resistivity on the power output of a TEC. However, the incorporation of scandium oxide together with porous metal might be a good candidate to reduce the work function and surface resistivity of a metal to a desirable amount ${ }^{65}$. Therefore, scandium and phosphorus oxide have the highest doping power in diamond lattice with the collector work function lower to $0.9 \mathrm{eV}$ (ref. 66). In recent times, a grid (graphene) mounted closer to the collector plate was found to lower the work function of the plate, reduce thermal losses and increase the efficiency of the TEC because the emitted electrons were under the vacuum level $^{64}$. NEA can also reduce the space-charge issue $^{67,68}$. The back-gated anode has shown promising application in the TEC because it reduces the space-charge effect and maintains low work function characteristics (Table 1$)^{2}$. Therefore, a magnet can be attached to the anode to reduce heat losses and channel the back emission spontaneously to the emitter.

\section{Space charge}

Space charge is the spreading of charge over the entire space and not only a point. Therefore, researchers have developed different techniques of eliminating its effect in TEC $^{22,23,49,57,84}$. Thus, the addition of cesium at the middle of the electrodes helped reduce the space-charge problem. However, there was a $30-50 \%$ loss in the efficiency of $\mathrm{TEC}^{15,86,87}$. The distance between emitter and collector was reduced to within 5-10 $\mu \mathrm{m}$ (ref. 15). With such a low distance, the emitted electrons are collected immediately as soon as they are emitted. An experiment was performed with small gap of $1.6 \mu \mathrm{m}$ between the emitter and collector $^{88}$. Also, a separation distance of $10 \mu \mathrm{m}$ generated a lot of heat loss, which negatively affected its efficiency $^{89}$. There was successful micromachining of $100 \mu \mathrm{m}$ emitter-collector distance that withstood elevated temperature of $1400 \mathrm{~K}$ (refs 26, 90, 91). Furthermore, a

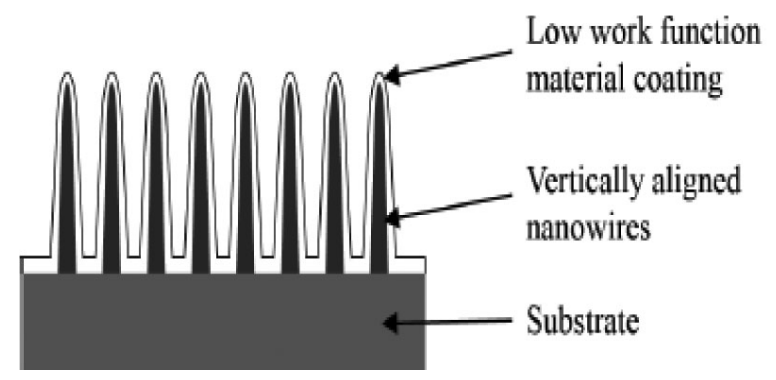

Figure 3. Surface engineering of emitter work function ${ }^{25,61}$. negative electron affinity method has yielded positive results in reducing the ripple effect of space charge in a $\mathrm{TEC}^{14}$. More so, the problem of space charge was overcome through insertion of the positive gate and magnetic field (Figure 4$)^{57}$. This latter solution helped produce lightweight TEC with graphene (transparent to the emitted electrons) as the grid $^{18,63}$. Such micromachining is tedious. A novel method was originally suggested by Mier et $a l .{ }^{57}$ and later modified by Olawole et $a l .{ }^{33}$.

\section{Theory of electricity generation thermionic energy converter}

In recent times, theorists have shown that the Richardson equation lacks merit to predict the current density of a TEC built using nanomaterials. Liang and $\mathrm{Ang}^{56}$ showed a theoretical efficiency of about $45 \%$ using eqs (1) and (2). Khatoon et al..$^{91}$ considered current density as a function of the cube power of temperature.

$$
\begin{aligned}
J= & \frac{e T^{3} k_{\mathrm{B}}^{3}}{\pi v_{\mathrm{F}}^{2} \hbar^{3}} \exp \left(-\frac{W-E_{\mathrm{F}}}{k_{\mathrm{B}} T}\right), \\
\eta= & {\left[\left(J_{\mathrm{c}}-J_{\mathrm{a}}\right)\left(\Phi_{\mathrm{c}}-\Phi_{\mathrm{a}}\right) /\right.} \\
& \left.\left(J_{\mathrm{c}}\left(\Phi_{\mathrm{c}}+2 k_{\mathrm{B}} T_{\mathrm{c}}\right)-J_{\mathrm{a}}\left(\Phi_{\mathrm{a}}+2 k_{\mathrm{B}} T_{\mathrm{a}}\right)\right)\right],
\end{aligned}
$$

where $A_{0}=e k_{B}^{3} / \pi v_{F}^{2} \hbar$ is the Richardson-Dushman constant for graphene $\left(115.8 \mathrm{Am}^{2} \mathrm{~K}^{-3}\right)^{18}, \Phi$ the work function of the material, $E_{\mathrm{F}}$ the Fermi energy, $v_{\mathrm{F}}$ the Fermi velocity, $T$ the temperature, $e$ the electronic charge, $\Phi_{\mathrm{c}}$ the work function of the cathode, $\Phi_{\mathrm{a}}$ the work function of the anode, $J_{\mathrm{c}}$ the cathode (emitter) current density, $J_{\mathrm{a}}$ the collector (anode) temperature, $T_{\mathrm{c}}$ the emitter temperature, $T_{\mathrm{a}}$ the collector temperature, $\hbar$ the reduced Planck's constant and $k_{\mathrm{B}}$ is the Boltzmann constant.

Olawole and $\mathrm{De}^{1}$ have shown the highest theoretical efficiency of $63.8 \%$ with their well-modelled energy

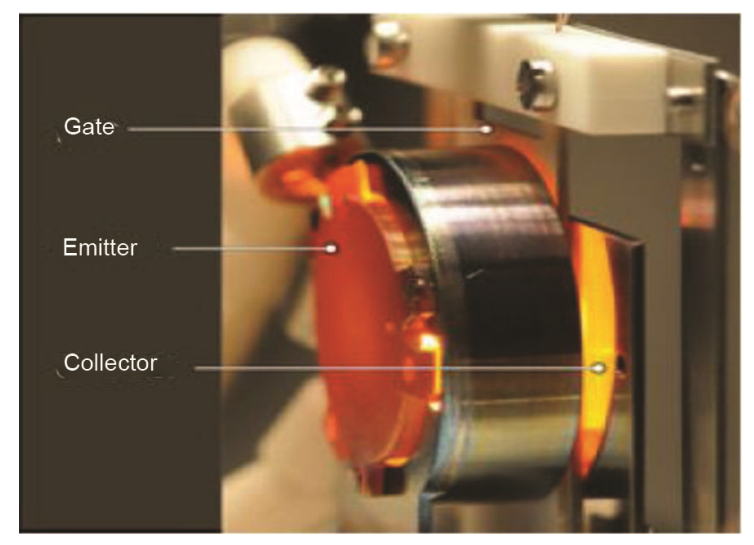

Figure 4. Effect of the gate in the emitter-collector interelectrode ${ }^{57}$. 
dynamic equations and modified Richardson-Dushman equation for nanomaterials ${ }^{1,33}$

$$
\begin{aligned}
& I_{0}(S-s) r a=\left[\frac{J_{\mathrm{e}} s\left(W_{\mathrm{e}}+2 k_{\mathrm{B}} T_{\mathrm{e}}\right)}{e}-\frac{J_{\mathrm{c}} s\left(W_{\mathrm{c}}+2 k_{\mathrm{B}} T_{\mathrm{c}}\right)}{e}\right] \\
& +\left[\varepsilon_{\mathrm{s}} \sigma s\left(T_{\mathrm{e}}^{4}-T_{\mathrm{a}}^{4}\right)+\varepsilon_{\mathrm{e}} \sigma s\left(T_{\mathrm{e}}^{4}-T_{\mathrm{c}}^{4}\right)\right], \\
& P_{\text {out }}=\left(J_{\mathrm{e}}-J_{\mathrm{c}}\right)\left(W_{\mathrm{e}}-W_{\mathrm{c}}\right) s / e, \\
& \eta=\left[\left(J_{\mathrm{e}}-J_{\mathrm{c}}\right)\left(W_{\mathrm{e}}-W_{\mathrm{c}}\right) / I_{0}(S-s) e\right],
\end{aligned}
$$

$$
\left.J=A_{0} T^{2} \exp \left(\left[\begin{array}{c}
{\left[\begin{array}{l}
r \alpha T+(1+r \alpha T) \\
\left(\frac{\pi^{2}}{12}\right)\left(\frac{k_{\mathrm{B}} T}{E_{\mathrm{F} 0}}\right)^{2}
\end{array}\right] E_{\mathrm{F} 0}+(1+r \alpha T)\left(\frac{7 \pi^{4}}{960}\right)} \\
+\left(\frac{k_{\mathrm{B}} T}{E_{\mathrm{F} 0}}\right)^{4}\left(E_{\mathrm{F} 0}\right)
\end{array}\right]\right) / k_{\mathrm{B}} T\right),
$$

where $A_{0}$ is the Richardson-Dushman constant for graphene $\left(120 \mathrm{Am}^{2} \mathrm{~K}^{-3}\right), W$ the work function of the material, $T$ the temperature, $W_{\mathrm{e}}$ the work function of the emitter, $W_{\mathrm{c}}$ the work function of the collector, $\alpha$ the coefficient of thermal expansion, $E_{\mathrm{F} 0}$ the Fermi energy, $k_{\mathrm{B}}$ the Boltzmann constant, $\eta$ the efficiency of solar thermionic power conversion, $r$ the reflection coefficient of the parabolic mirror, $\sigma$ and $\varepsilon_{\mathrm{s}}$ are the absorptivity and emissivity of the silicon carbide substrate surface on which the solar energy is focused, $\varepsilon_{\mathrm{s}}$ the emissivity of the graphene emitter surface facing the collector, $P_{\text {out }}$ the power output, $J_{\mathrm{e}}$ the emitter current density, $J_{\mathrm{c}}$ the collector temperature, $T_{\mathrm{e}}$ the emitter temperature and $T_{\mathrm{c}}$ is the collector temperature.

Kahtoon et $a l .{ }^{91}$ modified the Richardson-Dushman equation to show that both work function and Fermi energy are a function of temperature in a TEC

$$
\begin{aligned}
& J=\frac{e T^{3} k_{\mathrm{B}}^{3}}{\pi v_{\mathrm{F}}^{2} \hbar^{3}} \exp \left(-\frac{[(\phi(0)+\mu(0)(1-\alpha T))-}{k_{\mathrm{B}} T}\right) \\
& A_{0}=\frac{e k_{\mathrm{B}}^{3}}{\pi v_{\mathrm{F}}^{2} \hbar^{3}},
\end{aligned}
$$

where $A_{0}$ is the assumed Richardson-Dushman constant for graphene $\left(115.8 \mathrm{Am}^{2} \mathrm{~K}^{-3}\right)^{37}, \phi$ the work function of the material, $\mu$ the Fermi energy, $v_{\mathrm{F}}$ the Fermi velocity, $T$ the temperature, $T_{\mathrm{F}}$ the Fermi temperature, $e$ the electron- ic charge, $\hbar$ the reduced Planck's constant and $k_{\mathrm{B}}$ the Boltzmann constant.

\section{Conclusion}

There is an omission of emissivity in eq. (2), which will adversely affect the efficiency of the TEC. Thus the efficiency recorded by eq. (2) (ref. 93) was far less (18\%) than that by eq. (5) (ref. 1). Also, Kahtoon et al..$^{91}$ did not evaluate the efficiency of the TEC, which may be due to the weakness of the theory in predicting the efficiency of the TEC accurately. This study has shown the progress made in achieving a highly efficient thermionic energy converter in a real world. Specifically, the pace of advancement of surface engineering and nanoengineering towards commercialization of TEC is a signature to the fact that flexible TEC with higher performance is realizable.

1. Olawole, O. C. and De, D. K., Theoretical studies of thermionic conversion of solar energy with graphene as emitter and collector. J. Photon. Energy, 2018, 8, 1.

2. Yuan, H., Riley, D. C., Shen, Z.-X., Pianetta, P. A., Melosh, N. A. and Howe, R. T., Back-gated graphene anode for more efficient thermionic energy converters. Nano Energy, 2017, 32, 67-72.

3. Wanke, R., Voesch, W., Rastegar, I., Kyriazis, A., Barun, W. and Mannhart, J., Thermoelectronic energy conversion: concepts and materials. MRS Bull., 2017, 42, 518-524.

4. Schlichter, W., Die spontane elektronenemission glühender Metalle und das glühelektrische element. Ann. Phys., 1915, 352, 573-640.

5. Rasor, N. S. and Member, S., Thermionic energy conversion plasmas. IEEE Trans. Plasma Sci., 1991, 19, 1191-1207.

6. Rouklove, P., Thermionic Converter and Generator Development, Supporting Research and Advanced Development, Space Programs Summary 37-40, Jet Propulsion Laboratory, Pasadena, California, 31 August 1966, vol. IV, pp. 1-14.

7. Frank, T. G., Kern, E. A. and Booth, L. A., Application of thermionic conversion using a fusion reactor energy source: a preliminary assessment.

8. Fitzpatrick, G. O., Britt, E. J. and Moyzhes, B., Updated perspective on the potential for thermionic conversion to meet $21 \mathrm{st}$ century energy needs. In 97th Proceedings of the Thirty-Second Intersociety Energy Conversion Engineering Conference (Cat. No. 97CH6203) IEEE, Honolulu, Hawaii, 1997, vol. 2, pp. 1045-1051.

9. Koeck, F. A. M., Nemanich, R. J., Lazea, A. and Haenen, K., Thermionic electron emission from low work-function phosphorus doped diamond films. Diam. Relat. Mater., 2009, 18, 789-791.

10. Nemanich, R. J., Bilbro, G. L., Bryan, E. N., Koeck, F. A., Smith, J. R. and Tang, Y., Thermionic and field electron emission devices from diamond and carbon nanostructures. In Third International Nanoelectronics Conference (INEC), IEEE, Hong Kong, China, 2010, pp. 56-57.

11. Wei, X., Wang, S., Chen, Q. and Peng, L., Breakdown of Richardson's law in electron emission from individual self-Jouleheated carbon nanotubes. Sci. Rep., 2015, 4, 5102.

12. Powers, M. J. et al., Observation of a negative electron affinity for boron nitride. Appl. Phys. Lett., 1995, 67, 3912-3914.

13. Benke, S. M. and Venable, J. R., Operational testing and thermal modeling of a TOPAZ-II single-cell thermionic fuel element test stand. AIP Conf. Proc., 1995, 324, 495-501.

14. Gryaznov, G. M., 30th anniversary of the startup of Topaz - the first thermionic nuclear reactor in the world. At. Energy, 2000, 89, $510-515$. 
15. Thermionics Quo Vadis? National Academies Press, Washington, DC, USA, 2001.

16. Naito, H., Kohsaka, Y., Cooke, D. and Arashi, H., Development of a solar receiver for a high-efficiency thermionic/thermoelectric conversion system. Sol. Energy, 1996, 58, 191-195.

17. Smestad, G. P., Conversion of heat and light simultaneously using a vacuum photodiode and the thermionic and photoelectric effects. Sol. Energy Mater. Sol. Cells, 2004, 82, 227-240.

18. Begg, L. L., Streckert, H. S., Peltier, D. and Watson, J., Conceptua design of high power advanced low mass (HPALM) solar thermionic power system. In 37th Intersociety Energy Conversion Engineering Conference (IECEC'02), IEEE, 2002, pp. 7-11.

19. Yaghoobi, P., Moghaddam, M. V. and Nojeh, A., 'Heat trap' light-induced localized heating and thermionic electron emission from carbon nanotube arrays. Solid State Commun., 2011, 151, 1105-1108.

20. Buencuerpo, J. et al., Light-trapping in photon enhanced thermionic emitters. Opt. Express, 2015, 23, A1220.

21. Segev, G., Rosenwaks, Y. and Kribus, A., Limit of efficiency for photon-enhanced thermionic emission vs. photovoltaic and thermal conversion. Sol. Energy Mater. Sol. Cells, 2015, 140, 464-476.

22. Schwede, J. W. et al., Photon-enhanced thermionic emission from heterostructures with low interface recombination. Nature Commun., 2013, 4, 1576.

23. Kribus, A. and Segev, G., Solar energy conversion with photonenhanced thermionic emission. J. Opt., 2016, 18, 073001.

24. Lee, J.-H., Bargatin, I., Melosh, N. A. and Howe, R. T., Optimal emitter-collector gap for thermionic energy converters. Appl. Phys. Lett., 2012, 100, 173904.

25. Abdul Khalid, K. A., Leong, T. J. and Mohamed, K., Review on thermionic energy converters. IEEE Trans. Electron Devices, 2016, 63, 2231-2241.

26. Lee, J.-H. et al., Microfabricated thermally isolated low workfunction emitter. J. Microelectromech. Syst., 2014, 23, 11821187

27. Wanke, R., Hassink, G. W. J., Stephanos, C., Rastegar, I., Braun, W. and Mannhart, J., Magnetic-field-free thermoelectronic power conversion based on graphene and related two-dimensional materials. J. Appl. Phys., 2016, 119, 244507-4.

28. Wang, G., Chang, B., Li, X., Fu, R., Yang, L. and Wang, K., Solar energy conversion through thermally enhanced external photoelectric emission from $\mathrm{NaCsSb}$ photocathodes. Sol. Energy Mater. Sol. Cells, 2017, 159, 73-79.

29. Liu, L., Diao, Y. and Xia, S., High-performance GaAs nanowire cathode for photon-enhanced thermionic emission solar converters. J. Mater. Sci., 2019, 54, 5605-5614.

30. Smerdov, R. S., Mustafaev, A. S., Soukhomlinov, V. S., Spivak, Y. M. and Moshnikov, V. A., Nanostructured porous silicon and graphene-based materials for PETE electrode synthesys. In IEEE Conference of Russian Young Researchers in Electrical and Electronic Engineering (EIConRus), IEEE, Petersburg and Moscow, Russia, 2019, pp. 786-790.

31. Smerdov, R. S., Mustafaev, A. S., Spivak, Y. M. and Moshnikov, V. A., Porous silicon and graphene-based nanostructures for novel solar energy systems. J. Phys. Conf. Ser., 2018, 1135, 012038.

32. De, D. K. and Olukunle, O. C., A theoretical study on solar thermionic (thermo electronic) power conversion with a parabolic concentrator. IEEE, 2015, 1-7.

33. Olawole, O. C., De, D. K. and Oyedepo, S. O., Energy dynamics of solar thermionic power conversion with emitter of graphene. Proc. SPIE, 2016, 9932, 99320S.

34. Zanin, H. et al., Porous boron-doped diamond/carbon nanotube electrodes. ACS Appl. Mater. Interfaces, 2014, 6, 990-995.

35. Zhu, F. et al., Heating graphene to incandescence and the measurement of its work function by thermionic emission method. Nano Res., 2014, 7, 553-560.
36. Jurgens, R. F., High-temperature electronics applications in space exploration. IEEE Trans. Ind. Electron., 1982, IE-29, 107-111.

37. Wu, C., Optimal power from a radiating solar-powered thermionic engine. Energy Convers. Manage., 1992, 33, 279-282.

38. Olukunle, O. C. and De, D. K., Thermo-electronic solar power conversion with a parabolic concentrator. J. Semicond., 2016, 37, 024002 .

39. De, D. K. and Olawole, O. C., Modified Richardson-Dushman equation and modeling thermionic emission from monolayer graphene. Proc. SPIE, 2016, 9927, 1-7.

40. El-Genk, M. S. and Momozaki, Y., An experimental investigation of the performance of a thermionic converter with planar molybdenum electrodes for low temperature applications. Energy Convers. Manage., 2002, 43, 911-936.

41. Lamba, R. and Kaushik, S. C., Energy and exergy analysis of an irreversible thermionic generator. In Seventh Power India International Conference (PIICON), IEEE, Govt Engineering College, Bikaner, Rajasthan, India, 2016, pp. 1-6.

42. Datas, A., Hybrid thermionic-photovoltaic converter. Appl. Phys. Lett., 2016, 108, 143503.

43. Mishra, S. K., Kahaly, M. U. and Misra, S., Efficient utilization of multilayer graphene towards thermionic convertors. Int. J. Therm. Sci., 2017, 121, 358-368.

44. Xiao, G., Zheng, G., Qiu, M., Li, Q., Li, D. and Ni, M., Thermionic energy conversion for concentrating solar power. Appl. Energy, 2017, 208, 1318-1342.

45. Xiao, L., Wu, S.-Y. and Yang, S.-L., Parametric study on the thermoelectric conversion performance of a concentrated solardriven thermionic-thermoelectric hybrid generator. Int. J. Energy Res., 2018, 42, 656-672.

46. Hasan, M. M., Cuskelly, D., Sugo, H. and Kisi, E. H., Low temperature synthesis of low thermionic work function $\left(\mathrm{La}_{x} \mathrm{Ba}_{1-x}\right) \mathrm{B}_{6}$. J. Alloys Compd., 2015, 636, 67-72.

47. Lim, I. T., Lambert, S. A., Vay, J.-L. and Schwede, J. W., Electron reflection in thermionic energy converters. Appl. Phys. Lett., 2018, 112, 073906.

48. Bellucci, A. et al., Preliminary characterization of ST2G: solar thermionic-thermoelectric generator for concentrating systems. National Research Council (US). Committee on Thermionic Research and Technology; National Research Council (US). Aeronautics and Space Engineering Board, United States. Defense Threat Reduction Agency, 2015, 020007.

49. De, D. K. and Olawole, O. C., A three-dimensional model for thermionic emission from graphene and carbon nanotube. J. Phys. Commun., 2019, 3, 015004

50. Bao, L., Qi, X., Bao, T., and Tegus, O., Structural, magnetic, and thermionic emission properties of multi-functional $\mathrm{La}_{1-x} \mathrm{Ca}_{x} \mathrm{~B}_{6}$ hexaboride. J. Alloys Compd., 2018, 731, 332-338.

51. Hou, S. and Zhang, H., A novel solar assisted vacuum thermionic generator-absorption refrigerator cogeneration system producing electricity and cooling. Energy Convers. Manage., 2019, 187, 8392.

52. Zhang, X., Ang, Y. S., Du, J.-Y., Chen, J. and Ang, L. K., Graphene-based thermionic-thermoradiative solar cells: concept, efficiency limit, and optimum design. J. Clean. Prod., 2020, 242, 118444.

53. Jenkins, R., A review of thermionic cathodes. Vacuum, 1969, 19, 353-359.

54. Kirkwood, D. M. et al., Frontiers in thermionic cathode research. IEEE Trans. Electron Devices, 2018, 65, 2061-2071.

55. Hishinuma, Y., Geballe, T. H., Moyzhes, B. Y. and Kenny, T. W., Refrigeration by combined tunneling and thermionic emission in vacuum: Use of nanometer scale design. Appl. Phys. Lett., 2001, 78, 2572-2574.

56. Liang, S.-J. and Ang, L. K., Electron thermionic emission from graphene and a thermionic energy converter. Phys. Rev. Appl., $2015,3,014002$. 


\section{REVIEW ARTICLES}

57. Meir, S., Highly-efficient thermoelectronic conversion of solar energy and heat into electric power. J. Renew. Sustain. Energy, 2013, 5, 043127.

58. Wei, X., Chen, Q. and Peng, L., Electron emission from a twodimensional crystal with atomic thickness. AIP Adv., 2013, 3

59. Nemanich, R. J., Baumann, P. K., Benjamin, M. C., King, S. W., van der Weide, J. and Davis, R. F., Negative electron affinity surfaces of aluminum nitride and diamond. Diam. Relat. Mater., 1996, 5, 790-796.

60. Westover, T. L., Franklin, A. D., Cola, B. A., Fisher, T. S. and Reifenberger, R. G., Photo- and thermionic emission from potassium-intercalated carbon nanotube arrays. J. Vac. Sci. Technol. B, 2010, 28, 423-434.

61. Shamsudin, N. H., Abdul Khalid, K. A. and Mohamed, K. Synthesizing vertically aligned zinc oxide nanowires on borosilicate glass using vapor trapping approach. Adv. Mater. Res., 2014, 1024, 87-90.

62. Sugino, T., Kimura, C. and Yamamoto, T., Electron field emission from boron-nitride nanofilms. Appl. Phys. Lett., 2002, 80, 36023604 .

63. Go, D. B. et al., Thermionic energy conversion in the twenty-first century: advances and opportunities for space and terrestrial applications. Front. Mech. Eng., 2017, 3, 13.

64. Pan, T., Busta, H., Gorski, R. and Rozansky, B., Inverse tunneling of electrons in field emission heat engines. In 27th International Vacuum Nanoelectronics Conference (IVNC) IEEE, Engelberg, Switzerland, 2014, pp. 147-148.

65. Gibson, J. W., Haas, G. A. and Thomas, R. E., Investigation of scandate cathodes: emission, fabrication, and activation processes. IEEE Trans. Electron Devices, 1989, 36, 209-214.

66. Koeck, F. A. M., Nemanich, R. J., Lazea, A. and Haenen, K., Thermionic electron emission from low work-function phosphorus doped diamond films. Diam. Relat. Mater., 2009, 18, 789-791.

67. Smith, J. R., Bilbro, G. L. and Nemanich, R. J., Theory of space charge limited regime of thermionic energy converter with negative electron affinity emitter. J. Vac. Sci. Technol. B, 2009, 27, 1132-1141.

68. Smith, J. R., Increasing the efficiency of a thermionic engine using a negative electron affinity collector. J. Appl. Phys., 2013, 114, 164514.

69. Shimizu, M. et al., JSUS solar thermal thruster and its integration with thermionic power converter. AIP Conf. Proc., 1998, 420, 364-369.

70. Clark, P. N. et al., Solar thermionic test in a thermal receiver. AIP Conf. Proc., 2006, 813, 598-606.

71. Rufeh, F., Performance improvement of cesium thermionic converters by addition oxygen. In 7th Intersociety Energy Conversion Conference, San Diego, California, 1972.

72. Hansen, L. K., Hatch, G. L., Fitzpatrick, G. O. and Al, E., The plasmatron as an advanced performance thermionic converter. In In 11 th Intersociety Energy Conversion Engineering Conference, NV, USA, 1976, pp. 1630-1634.

73. Shimada, K., Low arc drop hybrid mode thermionic converter. In 12th Intersociety Energy Conversion Engineering Conference, Washington DC, USA, 1977, pp. 1568-1574.

74. Henne, R., Bradke, M. V. and Weber, W., Progress in the development of small flame heated thermionic energy converters. In Intersoc. In Energy to the 21st Century; Proceedings of the Fifteenth Intersociety Energy Conversion Engineering Conference, Seattle, Wash, 18-22 August 1980. Volume 3 (A80-48165 21-44) American Institute of Aeronautics and Astronautics, Inc., New York, 1980, pp. 2089-2094.

75. Goodale, D. B., Reagan, P., Miskolczy, G. and Al., E., Combustion performance of CVD silicon carbide thermionic diodes. In Energy to the 21st Century; Proceedings of the Fifteenth Intersociety Energy Conversion Engineering Conference, Seattle, Wash, 1980, pp. 2095-2097.
76. Smith, M. D., Manda, M. L. and Britt, E. J., Utilization of low temperature insulators and seals in thermionic converters. In Energy to the 21st Century; Proceedings of the Fifteenth Intersoc. Energy Converters. Engineering Conference, Seattle, Wash, 1980, 2098-2102.

77. Stark, G., Saunders, M. and Lieb, D., Thermionic converter output as a function of collector temperature. In Energy to the $21 \mathrm{st}$ Century; Proceedings of the Fifteenth Intersociety Energy Conversion Engineering Conference, Seattle, Wash, 1980.

78. Goodale, D., Lieb, D. and Neale, D., Solar thermionic energy converter experiment. In Proceedings of Intersoc Energy Convers Engineering Conference Thermo Electron Corporation; 4(CONF820814-), Waltham, MA, USA, 1982.

79. Dick, R. S., Britt, E. J., Fitzpatrick, G. O. and Al., E., High performance, close-spaced thermionic converters. In Proceedings of the Intersoc Energy Convers Engineering Conference Rasor Associates, Inc, Sunnyvale, California, USA, 1983.

80. El-Genk, M. S. and Luke, J. R., Performance comparison of thermionic converters with smooth and macro-grooved electrodes. Energy Convers. Manage., 1999, 40, 319-334.

81. El-Genk, M. S. and Momozaki, Y., An experimental investigation of the performance of a thermionic converter with planar molybdenum electrodes for low temperature applications. Energy Convers. Manage., 2002, 43, 911-936.

82. Momozaki, Y. and El-Genk, M. S., Investigations of the performance of grooved electrodes thermionic converters at collector temperatures up to 1023 K. Energy Convers. Manage., 2004, 45, 1153-1173

83. Liang, S.-J., Liu, B., Hu, W., Zhou, K. and Ang, L. K., Thermionic energy conversion based on graphene van der Waals heterostructures. Sci. Rep., 2017, 7, 46211.

84. Khalid, K. A. A., Leong, T. J. and Mohamed, K., Review on thermionic energy converters. IEEE Trans. Electron Devices, 2016, 63, 2231-2241

85. Baksht, F. G., Dyuzhev, G. A., Martsinovskiy, A. M., Moyzhes, B. Y., Pikus, G. Y., Sonin, E. B. and Yur'yev, V. G. , Thermionic converters and low-temperature plasma. Technical Report $\mathrm{N}$, Technical Information Center/DOE, 1978, vol. 80, pp. 17579.

86. Moyzhes, B. Y. and Geballe, T. H., The thermionic energy converter as a topping cycle for more efficient heat engines - new triode designs with a longitudinal magnetic field. J. Phys. D, 2005, 38, 782-786.

87. Littau, K. A. et al., Microbead-separated thermionic energy converter with enhanced emission current. Phys. Chem. Chem. Phys., 2013, 15, 1442-1446.

88. Belbachir, R. Y., An, Z. and Ono, T., Thermal investigation of a micro-gap thermionic power generator. J. Micromech. Microeng., 2014, 24, 085009.

89. Lee, J.-H., Bargatin, I., Melosh, N. A. and Howe, R. T., Optimal emitter-collector gap for thermionic energy converters. Appl. Phys. Lett., 2012, 100, 173904.

90. Misra, S., Upadhyay Kahaly, M. and Mishra, S. K., Thermionic emission from monolayer graphene, sheath formation and its feasibility towards thermionic converters. J. Appl. Phys., 2017, 121, 065102.

91. Khatoon, S. A., Ansari, M. M. and Ashraf, S., Effect of temperature-dependent work function and Fermi energy on thermionic emission current density in graphene. AIP Conf. Proc., 2018, 1953, 030239

92. Liang, S. J. and Ang, L. K., Electron thermionic emission from graphene and thermionic energy converter. Phys. Rev. Appl., 2015, 3, 014002 .

ACKNOWLEDGEMENTS. We thank Covenant University, Nigeria for providing the necessary facilities to carry out this work.

Received 21 January 2019; revised accepted 11 December 2019

doi: $10.18520 / \mathrm{cs} / \mathrm{v} 118 / \mathrm{i} 4 / 543-552$ 